\section{Fluoretação das águas de abastecimento público no Brasil: o olhar de lideranças de saúde}

\author{
Public water supply fluoridation in Brazil according \\ to health sector leaders
}

\author{
Fluorización de las aguas de abastecimiento \\ público en Brasil: el punto de vista de los líderes \\ en salud
}

\author{
1 Faculdade de Farmácia, \\ Odontologia e Enfermagem \\ Universidade Federal do \\ Ceará, Fortaleza, Brasil. \\ 2 Faculdade de Saúde \\ Pública, Universidade de São \\ Paulo, São Paulo, Brasil. \\ 3 Secretaria Municipal de \\ Saúde de São Paulo, São \\ Paulo, Brasil. \\ Correspondência \\ R. G. L. A. Ferreira \\ Faculdade de Farmácia \\ Odontologia e Enfermagem, \\ Universidade Federal \\ do Ceará. \\ Rua Monsenhor Furtado s/n, \\ Fortaleza, CE 60430-350, \\ Brasil. \\ reginalucenal@hotmail.com
}

\begin{abstract}
Various groups have opposed water supply fluoridation in Brazil, while others have supported the measure based on scientific evidence. This article describes the perceptions of delegates to the 13th National Health Conference on mandatory fluoridation of the country's public water supply. Interviews were processed using collective subject discourse analysis. A certain degree of misinformation persists regarding basic characteristics of water fluoridation, which is frequently confused with chlorination. The delegates' discourses showed a continuing need for public awareness-raising regarding fluoridation and the delegates' desire that the National Congress not take measures impacting public health without consulting society's stakeholders. However, most of the interviewees agreed that to repeal mandatory water fluoridation or loosen the control of its implementation could increase the incidence of tooth decay in the population.
\end{abstract}

Dental Caries; Drinking Water; Fluoridation
Regina Glaucia Lucena Aguiar Ferreira 1 Cláudia Maria Bógus 2 Regina Auxiliadora de Amorim Marques 3 Léa Maria Bezerra de Menezes 1 Paulo Capel Narvai ${ }^{2}$

\section{Resumo}

Desde sua implantação, a fluoretação das águas tem enfrentado oposição de alguns grupos, enquanto outros, baseados em evidência científica, apoiam a medida. Neste artigo, descrevem-se as percepções dos delegados à 13a Conferência Nacional de Saúde sobre a obrigatoriedade da fluoretação das águas de abastecimento público no Brasil. Como técnica de processamento de depoimentos, utilizou-se o Discurso do Sujeito Coletivo. Constata-se que, mais do que dúvidas, persiste certo grau de desinformação sobre aspectos básicos da fluoretação das águas, frequentemente confundida com a cloração. Torna-se evidente também a necessidade de permanente divulgação à sociedade de dados sobre a fluoretação da água e o desejo de que medidas que afetam a saúde pública não sejam tomadas pelo Congresso Nacional sem que se ouçam os setores interessados. Conforme a percepção majoritária dos participantes deste estudo, a revogação da obrigatoriedade de fluoretar as águas ou deficiências no controle sanitário de sua aplicação poderiam, no contexto brasileiro, piorar os índices populacionais de cárie dentária.

Cárie Dentária; Água Potável; Fluoretação 


\section{Introdução}

A fluoretação da água de abastecimento público, considerada uma das dez maiores conquistas de saúde pública do século XX,teve início com três estudos-piloto, realizados em 1945, nos Estados Unidos (Grand Rapids e Newburgh) e no Canadá (Brantford) 1. Esses estudos, amplamente monitorados, demonstraram a eficácia e a segurança do método 2,3. Desde sua implantação, a despeito de sua comprovada eficácia, segurança e custo-efetividade, a fluoretação das águas tem enfrentado oposição de alguns grupos, que utilizam como principais argumentos: violação do princípio ético da autonomia, questionamentos sobre a efetividade do método e a possibilidade de ocasionar riscos para a saúde 4 .

Países europeus não têm aderido à medida com unanimidade. Holanda, Suécia e Finlândia chegaram a fluoretar suas águas, porém, mais tarde, interromperam o processo. Outros países, como Suíça, Hungria, França e Dinamarca, nunca aderiram a esse método, embora os delegados desses países, na Assembleia Mundial da Saúde, sempre tenham votado favoravelmente à medida, em escala mundial 5. Essa decisão baseia-se no fato de que a eficácia relativa da fluoretação das águas é menor quando combinada com outras medidas preventivas da cárie, como os dentifrícios fluoretados. Por outro lado, tem havido novas adesões em alguns países. Recentemente, o governo de Queensland, na Austrália, decidiu fluoretar suas águas por observar que a ausência dessa medida resultou em uma pior condição de saúde bucal dos moradores dessa região, já que crianças de Queensland apresentavam até o dobro de prevalência de cáries, se comparadas às de regiões fluoretadas da Austrália 6 .

No Brasil, apesar do declínio na prevalência de cárie que se tem observado ao longo das últimas décadas 3 , houve uma crescente desigualdade na distribuição da doença, que afeta, em maior escala, as áreas mais submetidas à privação socioeconômica 7 . Barbato \& Peres 8 constataram forte associação entre a ausência da fluoretação das águas de abastecimento e as perdas dentárias na Região Nordeste do Brasil. A prevalência de perdas dentárias nos adolescentes que moravam em localidades sem água fluoretada foi $40 \%$ maior, quando comparada à prevalência de perdas daqueles que residiam em áreas com disponibilidade dessa medida. Além disso, a fluoretação de águas contribui para que as pessoas tenham outra medida correlata, que é o acesso à água tratada, talvez a mais importante ação de saúde pública. Apesar de a fluoretação de águas ser medida de promoção de saúde e prevenção da cárie dentária comprovadamente eficaz, e não obstante essa medida ser obrigatória (Lei no 6.050/1974 9) nos locais onde exista Estação de Tratamento de Água - ETA 5, muitas são as cidades brasileiras que não dispõem desse processo ou não possuem uma política de vigilância sanitária que controle de forma satisfatória a sua execução 10,11 .

No processo de implantação e expansão da fluoretação no país, a população brasileira participou das decisões apenas por meio dos seus representantes políticos, nos poderes executivo e legislativo. Não há, entretanto, registro, na literatura, sobre o tema nem sobre o que lideranças com atuação no setor de saúde pensam sobre a fluoretação da água.

O objetivo deste estudo é conhecer as opiniões dos delegados à 13ạ Conferência Nacional de Saúde sobre a obrigatoriedade da fluoretação e controle dos teores de flúor da água de abastecimento público no Brasil. Os delegados são atores sociais qualificados que participam de processos decisórios sobre saúde e sistema de saúde no país. Suas opiniões e percepções sobre essa temática são indicadores qualitativos do pensamento de, pelo menos, uma parcela da população brasileira: as lideranças em saúde.

\section{Métodos}

Trata-se de pesquisa descritiva, de natureza qualitativa, que consistiu na aplicação de questionário semiestruturado, contendo 19 questões sobre as relações água-saúde. Para este estudo, foi utilizada uma dessas questões, com foco específico na fluoretação das águas, formulada nos seguintes termos: "Hoje, os governos são obrigados por lei a controlar o nível de flúor nas águas de abastecimento público. Onde o nível é insuficiente, o produto deve ser adicionado. Está sendo discutido no Congresso Nacional um Projeto de Lei para acabar com isso, para desobrigar o governo dessa responsabilidade. Qual a sua opinião?".

Esse instrumento foi submetido a um préteste, com participantes da Conferência Municipal que não estavam na condição de delegados. A coleta dos dados ocorreu durante as etapas municipal (Fortaleza), estadual (Ceará) e nacional (Brasília) da Conferência. A pesquisa foi aprovada pelo Comitê de Ética em Pesquisa da Faculdade de Saúde Pública da Universidade de São Paulo, sob o Parecer no 1.723. A população de estudo, escolhida por conveniência, foram os delegados que, ao serem abordados e ouvirem os objetivos do estudo, concordaram em responder ao questionário, mediante a assinatura do termo de consentimento livre e esclarecido. 
Tendo em vista o objeto e a natureza do estudo, não houve preocupação em se constituir uma amostra representativa da população estudada. O critério de escolha foi participar da Conferência como delegado, e o de exclusão ter participado da pesquisa em uma etapa anterior da Conferência.

Para o tratamento dos dados, foi utilizada a técnica do Discurso do Sujeito Coletivo (DSC), que consiste num conjunto de procedimentos de tabulação e organização de dados discursivos, provenientes de depoimentos orais ou não ${ }^{12}$. O DSC possibilita que um determinado grupo social seja visto como autor e emissor de discursos comuns, compartilhados entre seus membros. Identificadas as expressões-chave, que são segmentos contínuos ou descontínuos dos discursos que revelam o principal conteúdo discursivo, elas foram agrupadas, conforme a ideia central que expressavam. Os discursos-síntese foram elaborados a partir dos depoimentos literais 13 . O trabalho de transcrição das respostas e sua organização e sistematização foi feito utilizando uma planilha eletrônica para processamento de dados. Os DSC foram obtidos a partir de sucessivas aproximações textuais de cada discurso individual, nas caselas da planilha eletrônica, para gerar cada DSC. Nesse processo, buscou-se eliminar reiterações e sobreposições formais e ajustou-se gramaticalmente o texto resultante. Conforme recomendação dos autores proponentes do método, os verbos foram colocados na primeira pessoa do singular. Os DSC foram analisados utilizando-se, como estratégia metodológica, a análise do discurso, levando-se, em consideração, a cultura, o contexto e as intenções dos sujeitos. As categorias analíticas foram definidas a posteriori, tendo emergido dos DSC, e se expressaram em três ideias centrais: contra o Projeto de Lei, a favor do Projeto de Lei e desconhecimento do Projeto de Lei.

\section{Resultados}

Participaram do estudo 310 delegados, de ambos os sexos, das cinco regiões do país, distribuídos da seguinte maneira: 56 da etapa municipal (Fortaleza), 143 da etapa estadual (Ceará) e 111 da nacional (Brasília). A distribuição, por segmento, foi a seguinte: 72 gestores/prestadores de serviços de saúde, 91 trabalhadores de saúde e 147 usuários.

Os discursos expressaram ideias centrais a favor e contra o Projeto de Lei, bem como certo grau de desinformação da população sobre o assunto, como se pode ver a seguir.

\section{Ideia central 1: contra o Projeto de Lei}

- DSC 1 - gestor/prestador: "É um absurdo esse Projeto de Lei. Acho francamente que esse é um retrocesso, pois se é dever do Estado proporcionar uma saúde de qualidade para todos, isso implica diretamente no oferecimento de abastecimento de água de qualidade. Como país emergente, o Brasil necessita olhar com mais atenção, principalmente aquele segmento populacional desfavorecido. A população de baixa renda não tem acesso a serviços odontológicos. Há uma boa faixa da população que desconhece a importância do cloro e flúor para sua saúde. A prevenção é a maior arma. Já é comprovado que a aplicação do flúor reduz o índice de cáries. Pelo nível de conscientização da nossa população, cabe ao governo fazer o controle e adicionar o flúor, porque muitas pessoas não saberão usar esse elemento, não adquirirão ou pela impossibilidade financeira ou por desleixo, trazendo consequências danosas. Esse Projeto de Lei só agravaria tal realidade! Devemos entrar em contato com pessoas representantes no Congresso para que a matéria seja rejeitada".

- DSC 2 - trabalhador de saúde: "Não concordo. Acho que o governo deve manter a obrigatoriedade. É de responsabilidade do governo monitorar e tomar providências para que se melhore a qualidade de vida da população, evitando o processo de doença e trabalhando com prevenção. Acho que seja de total responsabilidade do governo o gerenciamento sobre a qualidade da água de seus municípios. Esse Projeto de Lei não pode passar, vai de encontro aos princípios e normas técnicas da odontologia preventiva e às normas do SUS, uma vez que desprestigia a promoção da saúde e prevenção da cárie dental. O Projeto de Lei surge de uma forte influência dos países europeus que não usam flúor na água, desconsiderando as questões locorregionais e culturais do povo brasileiro. Considero errada essa decisão, pois prejudicará, principalmente, a população menos favorecida. É necessário que o governo detenha esse poder, pois a fluoretação é um meio barato e consegue atingir indistintamente toda a população. Enquanto a população não conseguir ter autonomia na prevenção e tratamento da cárie dentária, esta continua sendo a melhor forma de prevenção desta patologia tida como problema de saúde pública".

- DSC 3 - usuário: "Este assunto nem sequer deveria ser discutido. É dever do Estado a elaboração e cumprimento de políticas públicas que visem à promoção da saúde da população, e nossa função é cobrar sua elaboração e efetivação. Não deveria ser aprovado este projeto, uma vez 
que é uma forma de mantermos efetiva a saúde bucal, melhorando a condição de todos os brasileiros que, na grande maioria, não têm acesso ao acompanhamento e prevenção com profissional dentista. A população brasileira, principalmente a do Nordeste, apresenta altos índices da doença cárie (CPO-D maior que 3) e só a água fluoretada (flúor em baixas concentrações dosado com frequência) para diminuir o CPO-D. É questão de saúde pública. As comunidades são beneficiadas com oflúor. A cárie diminui, evitando, assim, mais gastos com saúde pública a partir de uma medida aparentemente simples. O governo é responsável pelo desenvolvimento da saúde e qualidade de vida de cada cidadão, portanto, não pode se furtar à sua responsabilidade de tratamento de água. Por que desobrigá-lo, se a qualidade da água é uma questão de saúde pública? Os nossos legisladores devem ser responsabilizados por isso. Penso eu que, daqui a pouco, vão tirar todas as obrigações importantes do governo! Quem foi, meu Deus, que teve esta ideia?".

\section{Ideia central 2: a favor do Projeto de Lei}

- DSC 1 - trabalhador de saúde: "Bom. A água não precisa ser com flúor, basta apenas o creme dental".

- DSC 2 - usuário: "Diferente do cloro, o flúor não chega a ser indispensável. Que seja desobrigado o governo dessa responsabilidade, e que os agentes de saúde sejam capacitados a passar para as comunidades".

É importante esclarecer que não houve discurso do gestor/prestador de serviços de saúde referente a essa ideia central, ou seja, favorável ao Projeto de Lei.

Ideia central 3: a população desconhece o Projeto de Lei

- DSC 1 - gestor/prestador: "Acho que a sociedade precisa conhecer mais, analisar e avaliar com mais responsabilidade todos os benefícios e malefícios do flúor, e o governo acatar a decisão final da sociedade".

- DSC 2 - trabalhador de saúde: "Eu não vou opinar sobre o assunto. Não tenho conhecimento". - DSC 3 - usuário: "Não sei opinar. Não conheço o teor do projeto nem as razões. Não conheço o motivo pelo qual se deixaria de adicionar o flúor. Tem bases científicas? Qual o papel do flúor? A questão deve ser seriamente discutida, creio que não é do conhecimento da população em geral a função do flúor. Que o povo seja esclarecido sobre essa necessidade e venha conhecer os motivos. Deveria haver um fórum com os usuários para saber a opinião pública. O Congresso de- veria consultar a população para não tomarem decisões contraditórias e até prejudiciais à saúde humana".

\section{Discussão}

Tendo em vista que no Brasil é possível encontrar água contendo flúor em níveis abaixo do recomendado para exercer uma ação preventiva (água hipofluoretada), em níveis ótimos (água isofluoretada) ou, ainda, em níveis acima do recomendado (água hiperfluoretada), é necessário que o Poder Público não apenas assegure a adição de flúor, quando necessário, mas também exerça controle sobre seus níveis, quando estiverem acima do padrão. Para isso, o país conta com legislação pertinente 9,14,15,16.

Preocupados com a elevada prevalência da cárie dentária que ainda persiste no Brasil e cientes do comprovado efeito do flúor na prevenção dessa doença, gestores/prestadores de serviços, trabalhadores de saúde e usuários posicionaram-se contra o Projeto de Lei. Eles consideram a fluoretação das águas de abastecimento uma política prioritária, merecedora de especial atenção do governo, haja vista o insuficiente acesso da população a outros métodos preventivos e a tratamento odontológico.

Em contrapartida, houve opiniões a favor do Projeto de Lei, ressaltando-se que essa manifestação ocorreu somente nas categorias de trabalhador de saúde e usuário. O gestor/prestador, consciente da necessidade dessa eficiente medida preventiva de cárie, considera-a de responsabilidade do governo, mas reconhece que a sociedade fica alheia à temática da fluoretação das águas.

Estudos demonstram que a fluoretação das águas beneficia proporcionalmente mais aqueles que dela mais necessitam, dado que seu impacto preventivo é diretamente proporcional à desigualdade social 17. Porém, Peres et al. 18 ponderam que, no contexto brasileiro, a medida não vem beneficiando a população de forma homogênea, já que a fluoretação se concentra nas regiões e municípios com melhores indicadores socioeconômicos, contribuindo para aumentar as desigualdades em saúde. Por outro lado, nas localidades onde a medida é adotada, embora o efeito preventivo beneficie a todos, esse é relativamente mais intenso entre os grupos de pior situação socioeconômica. Considera-se, pois, socialmente injusta a não adoção da medida ou sua interrupção ${ }^{3}$. Nesse sentido, o monitoramento dos contrastes em saúde bucal se constitui em importante ferramenta para a programação de intervenções socialmente apropriadas 7 . 
A necessidade de se esclarecer a população sobre esse assunto foi expressa pelas três categorias de delegados, que declararam precisar de mais informação para poder participar das discussões sobre o assunto. Consideram a sociedade inapta para cuidar de sua saúde bucal, em decorrência do baixo nível de educação/conscientização e, por esse motivo, enfatizam a necessidade do papel protetor do Estado.

Os discursos mostraram que, mesmo entre lideranças da área de saúde, predomina certa desinformação sobre o assunto, confundindo-se, frequentemente, por exemplo, a fluoretação com a cloração da água, o que caracteriza a existência de lacunas nos mecanismos de informação da sociedade. Esses achados corroboram aqueles encontrados por Lowry \& Adams 19, que constataram a necessidade de se manter a população mais bem informada a respeito da água de abastecimento, mediante a melhoria da disseminação das informações.

Para Bleicher \& Frota 10 , parece que a fluoretação das águas é considerada um assunto para entidades odontológicas, profissionais de saúde e governo, ficando a população com o papel de beneficiária passiva. As pessoas, muitas vezes, por não se apropriar adequadamente do assunto, podem se posicionar contra a fluoretação.

Alguns países realizaram consultas à população sobre a adição de flúor na água. Na Noruega, $34 \%$ dos adultos revelaram-se favoráveis à medida, enquanto $36 \%$ posicionaram-se contra, e o restante não opinou 20. Na África do Sul, 61,9\% dos respondentes manifestaram-se a favor da medida. Os que se posicionaram contra alegaram danos à saúde e aumento dos custos 21 .

Kerry et al. 22, descrevendo a opinião pública sobre fluoretação da água em Queensland, Austrália, revelaram que $70 \%$ dos entrevistados apoiavam a medida. Contrastando com esses dados, na Dinamarca, $48 \%$ dos participantes da pesquisa se opuseram à fluoretação da água de abastecimento 23 .

Entre os argumentos citados pelos adeptos da fluoretação da água de abastecimento público, estão: a diminuição da perda dentária, a "purificação" da água, entre outros. Com relação aos argumentos contra a fluoretação da água, os principais são: violação do princípio ético da autonomia, questionamentos sobre a efetividade do método e riscos para o ser humano 11.

Na Europa, em um estudo envolvendo 16 países, verificou-se que a maioria das pessoas se manifestou contra a fluoretação da água, estando presentes, dentre os argumentos mencionados, a "poluição" provocada pela presença do flúor e mudanças no sabor e no odor da água 24 .
Com relação à liberdade de escolha, o princípio ético da autonomia afirma que cada um deve escolher livremente entre as alternativas que lhe são apresentadas para decidir o que é "bom" e "adequado" para si, com base nos seus valores, expectativas, necessidades, prioridades e crenças pessoais. Contudo, em saúde pública, frequentemente, utiliza-se uma orientação ética baseada no princípio da utilidade social, que entende que o correto é beneficiar o maior número de pessoas 25 . No caso da fluoretação das águas, a medida pondera os benefícios para muitos e os riscos para alguns, sempre tentando minimizálos. O risco conhecido da medida, mesmo em localidades em que há adequado controle operacional e se faz vigilância sanitária sobre as ações, é o da produção de fluorose dentária em graus muito leve e leve, em cerca de $20 \%$ da população. Embora sem significado estético ou clínico relevantes, esse risco pode e deve ser minimizado pelo aprimoramento dos procedimentos operacionais e qualificação das ações de vigilância.

No tocante à efetividade do método, alegase que a diferença na prevalência de cárie entre regiões fluoretadas e não fluoretadas é menor do que no passado, especialmente nos países industrializados 1 . Alguns autores consideram, por isso, que a medida poderia ser considerada desnecessária em alguns países, embora reconheçam que a água fluoretada deva continuar sendo uma relevante medida de saúde pública em populações menos favorecidas 5 .

Com relação aos riscos à saúde humana, como doenças ósseas, câncer, infertilidade e outras, decorrentes da fluoretação das águas, não há evidência científica de que se constitua em fatores de risco 1,2. Desse modo, seu uso como argumento antifluoretação não é considerado cientificamente válido.

Constata-se que persistem dúvidas, entre os delegados à Conferência, sobre aspectos básicos relativos à fluoretação das águas como uma tecnologia de saúde pública segura e eficaz na prevenção da cárie e de baixo custo relativo.

Torna-se evidente, pelos discursos desses atores, a necessidade de ações que possibilitem divulgar para a sociedade, de modo permanente, informações sobre fluoretação da água. Igualmente clara é a aspiração, de todos os segmentos, de que medidas que afetam a saúde pública não sejam tomadas pelo Congresso Nacional sem que se ouçam amplamente todos os setores interessados.

Os delegados reagiram positivamente à possibilidade de que se realizem plebiscitos para que a sociedade possa decidir sobre a manutenção ou não da lei que torna obrigatória a fluoretação das águas. Os discursos indicam que, em um país 
como o Brasil, com muitas desigualdades sociais, onde muitos não têm acesso sequer a dentifrícios fluorados ou a outros veículos do flúor, liberar o governo da obrigação de proporcionar a toda a população a fluoretação das águas, a mais eficiente e eficaz medida preventiva de acesso potencialmente universal, poderia, segundo os delegados, piorar ainda mais os índices de cárie dentária da população.

\section{Resumen}

Desde su implantación, la fluorización del agua se ha encontrado con la oposición de diversos grupos, mientras que otros, basándose en evidencias científicas, sí apoyan la medida. En el presente artículo se describen las opiniones de los participantes en la $13^{a}$ Conferencia Nacional de Salud sobre la obligatoriedad de la fluorización de las aguas de abastecimiento público en Brasil. El método utilizado de procesamiento de testimonios ha sido el Discurso del Sujeto Colectivo. Parece que, más que dudas, lo que persiste en la actualidad es cierto grado de desinformación sobre los aspectos básicos de fluorización del agua. Resulta evidente la necesidad de la divulgación pública permanente de los datos sobre la fluorización del agua, así como el deseo de que el Congreso Nacional se abstenga de tomar medidas que afectan a la salud pública, sin antes escuchar a los sectores afectados. De acuerdo con la percepción mayoritaria de los participantes, la revocación de la obligatoriedad de fluorizar las aguas o las deficiencias en el control podrían aumentar los índices de caries dentales.

Caries Dental; Agua Potable; Fluoruración

\section{Colaboradores}

R. G. L. A. Ferreira e P. C. Narvai contribuíram desde a concepção do projeto de pesquisa até a revisão da versão final do manuscrito. C. M. Bógus, R. A. A. Marques e L. M. B. Menezes colaboraram na análise e interpretação dos resultados, revisão crítica do conteúdo e da versão final do manuscrito. 


\section{Referências}

1. Recommendations for using fluoride to prevent and control dental caries in the United States. MMWR Recomm Rep 2001; 50(RR-14):1-42.

2. McDonagh MS, Whiting PF, Wilson PM, Sutton AJ, Chestnutt I, Cooper J, et al. Systematic review of water fluoridation. BMJ 2000; 321:855-9.

3. Narvai PC. Cárie dentária e flúor: uma relação do século XX. Ciênc Saúde Coletiva 2000; 5:381-92.

4. Musto RJ. Fluoridation: why is it not more widely adopted? CMJA 1987; 137:705-8.

5. Pizzo G, Piscopo MR, Pizzo GG. Community water fluoridation and caries prevention: a critical review. Clin Oral Investig 2007; 11:189-93.

6. Australian Dental Association (Queensland Branch). Premier bligh bites the bullet on water fluoridation. http://www.fluoridationqld.com/ news-anna-bligh-water-fluoridation.html (acessado em 15/Mar/2008).

7. Antunes JLF, Peres MA, Mello TRC. Determinantes individuais e contextuais da necessidade de tratamento odontológico na dentição decídua no Brasil. Ciênc Saúde Coletiva 2006; 11:79-87.

8. Barbato PR, Peres MA. Perdas dentárias em adolescentes brasileiros e fatores associados: estudo de base populacional. Rev Saúde Pública 2009; 43:13-25.

9. Brasil. Lei Federal no 6.050, de 24 de maio de 1974. Dispõe sobre a obrigatoriedade da fluoretação das águas em sistemas de abastecimento. Diário Oficial da União 1974; 27 jul.

10. Bleicher L, Frota FHS. Fluoretação da água: uma questão de política pública - o caso do Estado do Ceará. Ciênc Saúde Coletiva 2006; 11:71-8.

11. Kalamatianos PA, Narvai PC. Aspectos éticos de produtos fluorados no Brasil: uma visão dos formuladores de políticas de saúde. Ciênc Saúde Coletiva 2006; 11:63-9.

12. Teixeira JJV, Lefèvre F. Significado da intervenção médica e da fé religiosa para o paciente idoso com câncer. Ciênc Saúde Coletiva 2008; 13:1247-56.

13. Lefèvre F, Lefèvre AMC, Teixeira JJV. O discurso do sujeito coletivo: uma nova abordagem metodológica em pesquisa qualitativa. Caxias do Sul: Editora da Universidade de Caxias do Sul; 2000.

14. Brasil. Portaria no 635, de 26 de dezembro de 1975. Aprova normas e padrões sobre a fluoretação da água de sistemas públicos de abastecimento. Diário Oficial da União 1974; 26 dez.
15. Ministério da Saúde. Portaria no 518, de 25 de março de 2004. Estabelece os procedimentos e responsabilidades relativas ao controle da vigilância da qualidade da água para o consumo humano e seu padrão de potabilidade e dá outras providências. Diário Oficial da União 2004; 26 mar.

16. Presidência da República. Decreto no 5.440, de 5 de maio de 2005. Estabelece definições sobre o controle de qualidade da água de sistemas de abastecimento e institui mecanismos e instrumentos para divulgação de informação ao consumidor sobre a qualidade da água para consumo humano. Diário Oficial da União 2005; 6 mai.

17. Kumar JV. Is water fluoridation still necessary? Adv Dent Res 2008; 20:8-12.

18. Peres MA, Fernandes LS, Peres KG. Inequality of water fluoridation in Southern Brazil - the inverse equity hypothesis revisited. Soc Sci Med 2004; 58:1181-9.

19. Lowry RL, Adams G. Attitudes to water fluoridayion in general dental practice in the North East of England. Br Dent J 2004; 196:423-4.

20. Helöe LA, Birkeland JM. The public opinion in Norway on water fluoridation. Community Dent Oral Epidemiol 1974; 2:95-7.

21. Chikte UME, Brand AA. Attitudes to water fluoridation in South Africa 1998. Part III. An analysis of pro- and anti-fluoridation attitudes in South Africa. SADJ 1998; 55:70-6.

22. Kerry MW, Duncan M, Kift R. Socio-economic differences in public opinion regarding water fluoridation in Queensland. Aust N Z J Public Health 2007; 31:336-9.

23. Schwarz E, Hansen ER. Public attitudes concerning water fluoridation in Denmark. Community Dent Oral Epidemiol 1976; 4:182-5.

24. Griffin M, Shickle D, Moran N. European citizens' opinions on water fluoridation. Community Dent Oral Epidemiol 2008; 36:95-102.

25. Fortes PAC, Zoboli, ELCP. Ética na saúde pública. In: Rocha AA, Chester LGC organizadores. Saúde pública bases conceituais. São Paulo: Editora Atheneu; 2008. p. 197-209.

Recebido em 18/Set/2013

Versão final reapresentada em 28/Jan/2014 Aprovado em 21/Fev/2014 